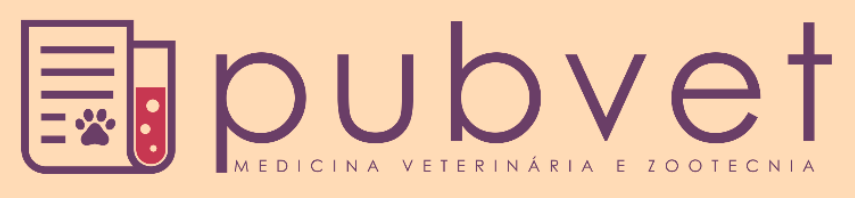

https://doi.org/10.31533/pubvet.v15n03a780.1-14

\title{
Respostas na fisiologia da digestão ruminal ao uso de taninos na alimentação de ruminantes
}

\author{
Jalise Fabíola Tontini ${ }^{1 *}$, Joseane Anjos da Silva ${ }^{2}$, Mariana de Souza Farias ${ }^{30}$, Cesar \\ Henrique Espirito Candal Poli ${ }^{4} \bullet$

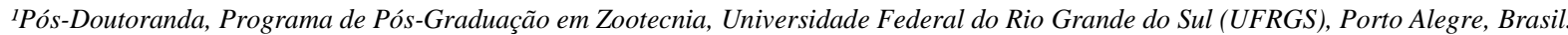 \\ ${ }^{2}$ Mestranda, Programa de Pós-Graduação em Zootecnia, UFRGS, Porto Alegre, Rio Grande do Sul/Brasil. \\ ${ }^{3}$ Doutora em Zootecnia, Programa de Pós-Graduação em Zootecnia, UFRGS, Porto Alegre, Rio Grande do Sul/Brasil. \\ ${ }^{4}$ Docente da Faculdade de Agronomia, UFRGS, Porto Alegre, Rio Grande do Sul/Brasil. \\ *Autor para correspondência, E-mail: jsetontini@yahoo.com.br
}

Resumo. A atividade pecuária no Brasil é basicamente representada pelo sistema pastoril. No entanto, as adversidades edafoclimáticas promovem uma falta de uniformidade na oferta e qualidade de forragem, acarretando na maior intensificação dos sistemas de produção. A busca por alternativas de alimentação visando à melhoria no desempenho animal, tem sido objeto de muitas pesquisas, como o uso de forrageiras adaptadas à determinadas condições ambientais. Geralmente, estas plantas podem apresentar compostos que alteram a produção animal, seja positiva ou negativamente. Dentre estes compostos, destacam-se os taninos condensados (TC) que são compostos polifenólicos oriundos do metabolismo secundário das plantas. Em concentrações elevadas (6 a $12 \%$ da matéria seca (MS)) eles reduzem a palatabilidade, o consumo, atividade enzimática, digestibilidade de proteínas e carboidratos, e consequentemente reduzem o desempenho animal. Todavia, quando esse consumo é médio ou baixo ( 2 a $5 \%$ da MS), permite uma eficiência na utilização da proteína dietética, formando complexos pelas ligações de hidrogênio, assim, acaba protegendo a proteína da degradação ruminal, aumentando o fluxo de aminoácidos para absorção intestinal. Além de melhorar a eficiência proteica da dieta, pode-se dizer que os TC reduzem a produção de metano e trazem benefícios no controle de parasitas gastrintestinais, melhora o desempenho reprodutivo, desenvolvimento fetal, a resposta do sistema imunológico, as concentrações séricas de hormônio, a produção de lã e lactação. O uso de plantas com baixa concentração de taninos condensados pode ser uma boa estratégia nutricional para ruminantes, desde que seu mecanismo de ação sobre o metabolismo proteico seja considerado. Esta revisão tem como objetivo, trazer algumas respostas ao uso de TC na alimentação de ruminantes, com o foco nas alterações da fisiologia digestiva do rúmen, que se torna responsável pelas consequências secundárias dos taninos sobre a produção animal.

Palavras chave: Compostos secundários, metabolismo, tanino condensado

\section{Responses in the physiology of ruminal digestion to the use of tannins in ruminant feeding}

Abstract. The livestock activity in Brazil is basically represented by the pastoral system. However, climatic adversities promote a lack of uniformity in forage supply and quality, leading to greater intensification of production systems. The search for feeding alternatives aiming to improve animal performance has been the object of many researches, such as the use of forages adapted to certain environmental conditions. Generally, these plants may have compounds that alter animal production, either positively or negatively. These 
compounds include condensed tannins (CT), which are polyphenolic compounds from secondary plant metabolism. At high concentrations ( 6 to $12 \%$ of dry matter (DM)) they reduce palatability, consumption, enzyme activity, protein and carbohydrate digestibility, and consequently reduce animal performance. However, when this consumption is medium or low (2 to $5 \%$ of DM), it allows an efficient use of dietary protein, forming complexes through hydrogen bonds, thus protecting the protein from ruminal degradation, increasing amino acid flow for intestinal absorption. In addition to improving the protein efficiency of the diet, CT can be said to reduce methane production, and bring benefits in the control of gastrointestinal parasites, improves reproductive performance, fetal development, immune system response, serum hormone concentrations, wool production and lactation. The use of plants with low concentration of condensed tannins may be a good nutritional strategy for ruminants, provided that its mechanism of action on protein metabolism is considered. This review aims to provide some answers to the use of CT in ruminant feeding, focusing on changes in rumen digestive physiology, which becomes responsible for the secondary consequences of tannins on animal production.

Keywords: Condensed tannins, metabolism, secondary compounds

\section{Respuestas en la fisiología de la digestión ruminal al uso de taninos en la alimentación de rumiantes}

Resumen. La actividad ganadera en Brasil está representada básicamente por el sistema pastoril. Sin embargo, las adversidades edafoclimáticas promueven una falta de uniformidad em el suministro y la calidad del forraje, lo que lleva a mayor intensificación de os sistemas de producción. La búsqueda de alternativas de alimentación con el objetivo de mejorar el rendimiento de los animales ha sido objeto de muchas investigaciones, como el uso de forrajes adaptados a ciertas condiciones ambientales. Generalmente, estas plantas pueden tener compuestos que alteran la producción animal, ya sea positiva o negativamente. Estos compuestos incluyen los taninos condensados (TC), que son compuestos polifenólicos del metabolismo secundario de la planta. A altas concentraciones (6 a 12\% de materia seca (MS)) reducen la palatabilidad, el consumo, la actividad enzimática, la digestibilidad de proteínas y carbohidratos y, em consecuencia, reducen el rendimiento animal. Sin embargo, cuando este consumo es medio a bajo ( 2 a $5 \%$ de MS), permite un uso eficiente de la proteína de la dieta, formando complejos a través de enlaces de hidrógeno, protegiendo así la proteína de la degradación ruminal, aumentando el flujo de aminoácidos para absorción intestinal. Además de mejorar la eficiencia proteica de la dieta, se puede decir que la TC reduce la producción de metano y aporta beneficios para controlar los parásitos gastrointestinales, mejorar el rendimiento reproductivo, el desarrollo fetal, la respuesta del sistema inmunitario y las concentraciones de hormonas séricas, producción de lana y lactancia. El uso de plantas con baja concentración de taninos condensados puede ser una buena estrategia nutricional para los rumiantes, siempre que se considere su mecanismo de acción sobre el metabolismo de las proteínas. Esta revisión tiene como objetivo aportar algunas respuestas al uso del TC em la alimentación de rumiantes, centrándose em los cambios en la fisiología digestiva del rumen, que se hace responsable de las consecuencias secundarias de los taninos em la producción animal.

Palabras clave: Compuestos secundarios, metabolismo, taninos condensados

\section{Introdução}

Nas últimas décadas as pesquisas na área de nutrição de ruminantes têm buscado alternativas de alimentação visando à melhoria no desempenho animal, com objetivo de manipular o ecossistema microbiano do rúmen, e assim, aumentar a eficiência do seu metabolismo (Valadares Filho et al., 2011). Neste cenário, ganha destaque os compostos secundários presentes nas plantas, como moduladores na fermentação ruminal e no metabolismo proteico, com reflexo positivo no desempenho e sanidade animal 
(Hart et al., 2008). As pastagens que cobrem uma significativa área no Brasil apresentam compostos secundários com potencial para incrementar a produção e produtividade dos ruminantes.

Entre esses compostos secundários, destaca-se o tanino condensado (TC), que são polímeros de flavonoides encontrados em espécies de plantas consumidas por ruminantes (Muir, 2011). O TC é um composto polifenólico que está relacionado com a sobrevivência das plantas (Huang et al., 2018). Quando presente em média ou baixa concentração ( 2 a $5 \%$ da MS), o consumo de tanino condensado reduz a proteólise ruminal pela capacidade de se complexar a proteína oriunda da dieta, tornando-a indisponível para a microbiota ruminal, formando complexos através de ligações de hidrogênio (Frutos et al., 2002). Com isso, a proteína ingerida é absorvida na luz intestinal, aumentando a eficiência na absorção de aminoácidos, possibilitando maior desempenho, pois serão utilizados na deposição de músculo com reflexo no ganho de peso (Kyriazakis et al., 2010). O uso de plantas com baixa concentração de taninos condensados pode ser uma boa estratégia nutricional para ruminantes, desde que seu mecanismo de ação sobre o metabolismo proteico seja considerado.

Além dos efeitos nutricionais, os taninos condensados possuem um considerável efeito antihelmíntico, por favorecer a recuperação do epitélio e do sistema imune frente a verminose, assim como, por impedir o desenvolvimento das larvas no hospedeiro (Yoshihara et al., 2013). Apesar da grande eficiência e contribuição dos fármacos na melhora de produtividade de rebanhos, no momento atual, devido ao aumento contínuo do número de populações de helmintos resistentes aos antiparasitários disponíveis, enfatiza a necessidade de investimento em novas formas de controle (Scott et al., 2013). Neste aspecto o TC traz grandes perspectivas, pois tem se mostrado como um composto estratégico que visa a redução da infecção por parasitas gastrintestinais, além, de poder ser utilizado como controle parasitário ecologicamente sustentável.

Portanto, a incorporação do uso de compostos secundários na criação animal pode incrementar a produção e melhorar a sanidade dos animais no sistema de produção a pasto. Além disso, vai de encontro com as exigências dos consumidores de proteína animal, que buscam cada vez mais produtos oriundos de sistemas produtivos com o mínimo de impacto ambiental e segurança alimentar sem a presença de resíduos químicos nos alimentos.

\section{Taninos: definição e características fito químicos}

Taninos são polifenóis com peso molecular entre 500 e 3.000 daltons. Fazem parte de um grupo de compostos secundários presente nas plantas, e podem ser encontrados em caules, cascas, folhas, flores ou sementes, abrigados dentro dos vacúolos, principalmente em plantas dicotiledôneas (Puchala et al., 2005; Seigler, 2003). Os taninos foram originalmente reconhecidos e utilizados para o curtimento do couro, devido à sua capacidade para se ligarem com as proteínas da pele (McMahon et al., 2000). O termo "tannin" refere-se a "tanning" que em português significa curtimento, ou conservação de peles para criar o couro. Além disso os taninos também contribuem para a adstringência de muitas bebidas populares, por exemplo, chá e vinho (Waghorn et al., 1990).

A primeira definição fito química de tanino foi proposta em 1962 por Bate-Smith (1962) "todos os compostos fenólicos solúveis em água, com um peso molecular situado entre 500 e 3000 Da, cujas principais propriedades (para além das reações características dos compostos fenólicos) são a de formarem complexos insolúveis com os alcaloides, gelatina e outras proteínas".

Os compostos fenólicos são substâncias que contêm pelo menos um grupo hidroxilo ligado ao anel benzênico (fenol) e que podem conter outros substituintes na sua estrutura tais como açúcares ou ácidos orgânicos. São conhecidos milhares de compostos fenólicos nas plantas que podem ser divididos em diversos grupos de acordo com a sua estrutura química. O grupo dos flavonoides é o mais diversificado em termos estruturais e subdivide-se em diversas classes (antocianinas, flavonas, chalconas, flavanonas, flavonóis, di-hidroflavonóis, flavan-4-ois, flavan-3,4-diois e flavan-3-ois). A classe dos flavan-3-ois é provavelmente a mais abundante porque constitui a unidade fundamental das proantocianidinas ou taninos condensados, que são muito abundantes na natureza (Haslam, 1989). Definir taninos quimicamente é muito difícil, pois esse termo engloba uma diversidade de oligômeros e polímeros. Portanto, resumidamente, os taninos são um grupo de compostos fenólicos heterogêneos de alto peso molecular com capacidade para formar complexos reversíveis ou irreversíveis com proteínas 
(principalmente), polissacarídeos (celulose, hemicelulose, pectina etc), saponinas, alcaloides, ácidos nucleicos, minerais e outras macromoléculas (Frutos et al., 2004; Haslam, 1989).

Tradicionalmente, os taninos são divididos em dois grupos baseados nos tipos estruturais: hidrolisável e condensado (Figura 1). Taninos hidrolisáveis (TH), são passíveis de serem degradados por hidrólise química ou enzimática nas várias unidades estruturais que os compõem (Lotfi, 2020). São constituídos por uma parte fenólica (ácido gálico e/ou ácido hexahidroxidifênico) e uma unidade de hexose (normalmente a glucose) ligadas por um éster (Frutos et al., 2004; McMahon et al., 2000). O TH pode ser hidrolisado por aquecimento com ácido fraco, em contraste os taninos condensados podem sofrer uma degradação oxidativa somente pelo ácido mineral quente (McMahon et al., 2000).

A Gallic acid<smiles>O=C(O)c1cc(O)c(O)c(O)c1</smiles>

Ellagic acid<smiles>O=c1oc2c(O)c(O)cc3c(=O)oc4c(O)c(O)cc1c4c23</smiles><smiles>O=C(OCC1OC(OC(=O)c2cc(O)c(O)c(O)c2)C(OC(=O)c2cc(O)c(O)c(O)c2)C(OC(=O)c2cc(O)c(O)c(O)c2)C1OC(=O)c1cc(O)c(O)c(O)c1)c1cc(O)c(O)c(O)c1</smiles>

B<smiles>Oc1cc(O)c2c(c1)OC(c1ccc(O)c(O)c1)C(O)C2</smiles>

Flavan-3,4-diol (leucoanthocyanidin)<smiles>Oc1cc(O)c2c(c1)OC(c1ccc(O)c(O)c1)C(O)C2O</smiles>

Condensed tannin

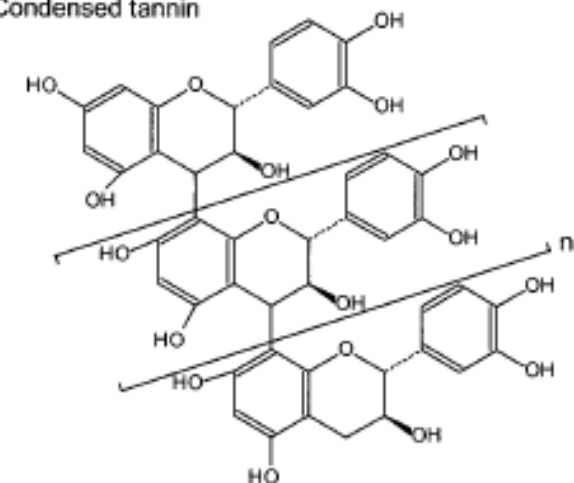

Figura 1. Componentes estruturais de taninos hidrolisáveis (A) e condensados (B). A) Taninos hidrolisáveis podem conter ácidos gálico ou elágico ligados por um éster e uma unidade de hexose. B) Taninos condensados são polímeros de flavan-3-ol e / ou flavan-3,4-diol (McMahon et al., 2000).

Os taninos condensados (TC), são polímeros de derivados fenólicos complexos, ligados por pontes carbono-carbono ou carbono-oxigênio-carbono, cuja ligações são mais resistentes à ruptura do que aquelas dos TH (Haslam, 1989). São também denominados flavan-3-ol (por exemplo, catequina) ou flavan-3,4-diol (proantocianidinas), com variados pesos moleculares (Leinmüller et al., 1991). As proantocianidinas são mais largamente distribuídas do que os taninos hidrolisáveis e são responsáveis pelos pigmentos vermelhos, roxos e azuis nas flores, frutos, sementes, caules e folhas (Haslam, 1989). Taninos condensados são sintetizados a partir de precursores do acetato e ácido chiquímico. Existe uma diversidade na estrutura química dos TC, devido à enorme variação dos seus monômeros constitutivos, estereoquímica, tamanho dos polímeros, as ligações intermoleculares, a dinâmica da sua localização, concentração e composição durante a fase de desenvolvimento da planta. A mudança dessas 
características pode influenciar a capacidade que os TC têm para se complexar com outras moléculas (McMahon et al., 2000).

A afinidade dos TC com as proteínas está diretamente relacionada ao número formado de grupos fenólicos. Estes grupos fornecem os pontos onde podem ocorrer a ligação com os grupos carbonila dos peptídeos. O alto peso molecular e a grande flexibilidade estrutural dos taninos favorecem a formação desses complexos. Além disso, as proteínas ricas em prolina possuem maior afinidade por TC com estruturas flexíveis (Frutos et al., 2004). As ligações entre TC e proteínas podem acontecer por quatro tipos de ligações:

1. Ligações de hidrogênio (reversíveis e dependentes do $\mathrm{pH}$ ) entre os radicais hidroxilo dos grupos fenólicos e o oxigênio dos grupos amida nas ligações peptídicas de proteínas;

2. por interações hidrofóbicas (reversíveis e dependente de $\mathrm{pH}$ ) entre o anel aromático dos compostos fenólicos e as regiões hidrofóbicas da proteína;

3. por ligações iônicas (reversível) entre o íon fenolato e o sítio catiônico da proteína (exclusivo ao TC) e

4. com a ligação covalente (irreversível) da oxidação dos polifenóis de quinonas e a sua subsequente condensação com grupo nucleifílico da proteína. As ligações de hidrogênio e hidrofóbicas são as mais importantes (Frutos et al., 2004; Kumar \& Singh, 1984).

\section{Efeitos dos Taninos na alimentação de ruminantes}

$\mathrm{Na}$ produção animal, considera-se que os TCs possuem efeitos adversos e podem apresentar benefícios para a nutrição de ruminantes, dependendo da quantidade consumida, da sua estrutura e peso molecular. Em concentrações elevadas (6 a 12\% da MS) eles reduzem a palatabilidade, o consumo, atividade enzimática, digestibilidade de proteínas e carboidratos, e consequentemente, reduzem o desempenho animal. No entanto, quando esse consumo é médio ou baixo ( 2 a $5 \%$ da MS), permite uma eficiência na utilização da proteína dietética, formando complexos com ligações de hidrogênio, assim, acaba protegendo a proteína da degradação ruminal e tornando-a uma "bypass", aumentando o fluxo de aminoácidos para absorção intestinal (Frutos et al., 2002; Naumann et al., 2017). Além de melhorar a eficiência proteica da dieta, pode-se dizer que os TC reduzem a produção de metano, e trazem benefícios no controle de parasitas gastrintestinais, melhora o desempenho reprodutivo, desenvolvimento fetal, a resposta do sistema imunológico, as concentrações séricas de hormônio, a produção de lã e lactação (Alonso-Díaz et al., 2010; Tedeschi et al., 2014).

\section{Efeitos adversos}

\section{Redução do consumo voluntário}

Segundo Frutos et al. (2002) o fornecimento de doses maiores (6 a 12\% na MS) de TC na dieta de ruminantes pode causar redução no consumo voluntário e redução na eficiência do processo digestivo. O principal mecanismo responsável pela diminuição do consumo voluntário, é em grande parte atribuído a formação de complexos entre TC e as glicoproteínas salivares, ou via uma ação direta com os receptores de sabor, dando a sensação de adstringência e diminuindo a palatabilidade da forragem (Frutos et al., 2004; Naumann et al., 2017; Reed, 1995).

Os efeitos adversos dos TC já vêm sendo estudados há muitos anos. Estudo realizado por Barry \& Duncan (1984) demostrou que o fornecimento de TC oriundos do Lotus Pedunculatus em concentração superior à 50g.kg-1 de matéria seca reduziu a ingestão de energia metabolizável, devido tanto a redução do consumo voluntário, quanto da digestão da matéria orgânica. A redução no processo digestivo se dá principalmente pela diminuição da degradação ruminal, especialmente da fibra, que provocaria um maior tempo de ruminação (Waghorn, 2008). Estudo realizado por Narjisse et al. (1995) com objetivo de avaliar os efeitos da infusão ruminal de taninos sob o consumo voluntário, a fim de inibir a influência da palatabilidade, observaram redução de $8 \%$ no consumo de ração. Segundo Frutos et al. (2004) quando há um retardo na digestão de matéria seca no rúmen, acaba prejudicando o esvaziamento do trato digestivo, gerando sinais para os centros nervosos envolvidos no controle do consumo que o animal está saciado "cheio".

Esse retardamento da digestão do alimento, pode estar relacionado com o efeito inibitório do TC sobre a atividade enzimática microbianas (bacterianas e fúngicas), principalmente sobre enzimas pectinolíticas e celulolíticas no fluido ruminal inibindo sua atividade (McSweeney et al., 2001). Uma 
vez os TC se complexando com essas enzimas interferem no seu potencial para degradar os nutrientes. Além das enzimas, os TC têm a capacidade de combinar com proteínas dietéticas, polímeros tais como celulose, hemicelulose, pectina, e minerais, retardando a digestão dos mesmos (McSweeney et al., 2001). Taninos, também são agentes quelantes, e isso pode reduzir a disponibilidade de certos íons metálicos necessário para o metabolismo de microrganismos do rúmen (Frutos et al., 2004).

Além disso, quando em elevada concentração, o TC apresenta efeito bactericida e/ou bacteriostático sobre as bactérias (McSweeney et al., 2001), principalmente, as degradadoras de fibra, que pode reduzir sua degradação devido a menor quantidade de bactérias para fermentação, acarretando em menor quantidade de energia oriunda dos ácidos graxos voláteis que são as principais fontes energéticas para os ruminantes, com isso, pode comprometer a absorção dos aminoácidos oriundos da dieta no intestino delgado por déficit de glicose. Em revisão feita por Patra \& Saxena (2010), eles apontam que além da privação de substrato para o crescimento microbiano, as atividades antimicrobianas dos TC podem ser de forma direta, e essa pode ser caracterizada pelas interações entre TC e as enzimas extracelulares e a parede celular de bactérias, causando alterações morfológicas na parede celular e induzindo o rompimento da membrana, inibindo o transporte de nutrientes para a célula com consequente retardo do crescimento do organismo.

Apesar das atividades antimicrobianas dos TC, alguns autores identificaram várias espécies de bactérias que conseguem tolerar o TC. Incluindo a Streptococcus gallolyticus, Streptococcus bovis, Streptococcus caprinus, entre outras. Alguns mecanismos têm sido propostos para a resistência das bactérias aos TC, como por exemplo, a segregação de glicoproteínas que formam uma camada protetora em torno das células e assim protegendo-as contra a ação do TC. Mecanismo de tolerância das bactérias aos taninos também envolvem a degradação de taninos pelas bactérias (Patra \& Saxena, 2010).

Kamra (2005) afirma que ruminantes que se alimentam continuamente com dietas ricas em taninos, geralmente desenvolvem uma microflora tolerante a alta quantidade de tanino. Como exemplo, caprinos selvagens e camelos que se alimentam de plantas ricas em taninos, são capazes de tolerar devido a presença de bactérias na microflora ruminal que são resistentes ao tanino como Streptococcus caprinus e Selenomonas ruminantium.

Além dessa adaptação dos animais devido à resistência de alguns microrganismos no rúmen, AlonsoDíaz et al. (2010) apontam algumas evidências de adaptação fisiológica de pequenos ruminantes para ingestão de plantas ricas em taninos. Esses autores mostram que ovinos e caprinos têm capacidade de aumentar o tamanho das glândulas salivares de forma a produzir maior volume de saliva, o que pode favorecer a formação de complexos solúveis de tanino-proteína, ou auxiliar na deglutição do alimento e inibir a ação do tanino no rúmen. Além disso, alguns animais em sistemas de pastejo tornam-se mais seletivos, consumindo espécies taniníferas em menores quantidades ou misturadas com forragens desprovidas de taninos. Além disso, caprinos e ovinos apresentam como estratégia para ingestão de plantas com elevada concentração de TC, capacidade de aumentar a produção e liberação de prolina via saliva, como o TC apresenta elevada afinidade por esta proteína, ao atingir o rúmen, ocorre a formação de TC-proteína (prolina), complexo este que reduzirá os efeitos adversos sobre a fermentação ruminal que poderia ser causada pela presença de alto TC (McMahon et al., 2000; Waghorn, 2008).

\section{Intoxicação por taninos hidrolisáveis}

A intoxicação dos ruminantes por taninos também foi relatada por alguns autores. Os taninos hidrolisáveis são mais solúveis em água e têm menor peso molecular e maior susceptibilidade à hidrólise enzimática e não enzimática do que os taninos condensados (Jeronimo et al., 2016). Existem algumas plantas que são consideradas tóxicas devido a elevada concentração de taninos hidrolisáveis. Estes quando ingeridos pelos ruminantes, sofrem hidrólise no rúmen e convertem os taninos hidrolisáveis em metabólitos de baixo peso molecular liberando ácidos fenólicos (gálico, caféico, elágico) por hidrólise ácida (Sgarbieri, 1996). Esses metabólitos entram na circulação sanguínea causando necrose, principalmente no fígado e rins, uma vez que em níveis altos no sangue estes superam a capacidade de desintoxicação desses órgãos (Makkar et al., 1995).

\section{Efeitos benéficos}




\section{Taninos condensados e metabolismo proteico}

Um dos principais nutrientes na dieta dos ruminantes é a proteína, embora o seu metabolismo seja um pouco complicado. A proteína oferecida na dieta não será a única fonte de aminoácido para a absorção no intestino delgado, uma vez que o fornecimento de aminoácidos provém também da síntese microbiana. Os ruminantes vivem em simbiose com os microrganismos ruminais. O hospedeiro (animal) fornece a partir do alimento, substrato para os microrganismos sobreviverem e estes em troca fornecem a proteína microbiana (Nagaraja et al., 2012; Stewart et al., 2012). As bactérias são os principais microrganismos que degradam a proteína da dieta à peptídeos, aminoácidos e amônia. Juntamente com a digesta esses microrganismos saem do rúmen e chegam até o abomaso, onde sofrem uma degradação enzimática e química das proteínas. A quantidade de proteína que flui do rúmen é um fator muito importante que pode determinar a produtividade dos ruminantes, se parte da proteína da forragem escapar da degradação ruminal e ser disponível para absorção pós-ruminal, isso pode levar a um aumento da eficiência proteica (Patra \& Saxena, 2010).

As pesquisas na área de nutrição de ruminantes têm buscado alternativas para manipular o ecossistema microbiano no rúmen com objetivo de aumentar a eficiência do seu metabolismo e consequentemente melhorar a produtividade animal. Alguns aditivos químicos foram introduzidos na dieta dos ruminantes, tais como, antibióticos, ionóforos, agentes defaunadores, entre outros, para promover o crescimento microbiano, melhorar a utilização dos nutrientes e reduzir a produção de metano (Cagle et al., 2020; Cocito, 1979; Goodrich et al., 1984). Todavia, existe uma preocupação pela quantidade de resíduos químicos presentes nos produtos de origem animal, resultantes desse processo, e isso sugere aos pesquisadores encontrar alternativas mais seguras, aliadas ao menor custo para ser utilizada na produção animal (Patra \& Saxena, 2010).

Neste contexto, ganham destaque plantas com a presença de compostos secundários, dentre esses compostos se destacam os TC, que dependendo da quantidade ofertada na dieta podem melhorar a utilização da proteína, formando complexos entre TC-Proteína, e assim protegendo-a da degradação no rúmen. O mecanismo de ação dos TC sobre a proteína ocorre com a formação de complexos estáveis em $\mathrm{pH}$ 3,5 e 7, mas se dissociam quando o $\mathrm{pH}$ cai abaixo de 3,5, como ocorre no abomaso (pH 2,5-3) ou é superior a 7, como ocorre no duodeno (pH 8) (Barry \& Manley, 1984; Van Soest, 1994).

Um mol de tanino condensado (TC) pode se ligar à 12 moles de proteína por ligações de hidrogênio (Jeronimo et al., 2016) entre os grupos fenólicos dos taninos e determinados sítios das proteínas, o TC entra nos espaços interfibrilares das proteínas (Bruneton, 1995) impedindo a aderência da microbiota ruminal nestas, ou seja, promove uma proteção da proteína dietética da degradação ruminal. Como vantagem, pode ser que a proteína dietética apresente melhor perfil de aminoácidos e de melhor digestão quando comparada à proteína microbiana que é de $80 \%$ de digestibilidade. Assim, o animal poderá obter um perfil de aminoácidos diferenciado em relação ao que não sofre influência do TC sobre a proteína, no qual o maior aporte proteico será de origem microbiana. Estes aminoácidos podem gerar um melhor desempenho, pois serão utilizados na deposição de músculo com reflexo no melhor ganho de peso, além de favorecer a recuperação do epitélio e do sistema imune frente a verminoses (Kyriazakis et al., 2010; Minho et al., 2008).

Tedeschi et al. (2014) fizeram um compilado de pesquisas que avaliaram a digestão e absorção de aminoácidos (AA) por meio do abomaso de ovinos alimentados com diferentes cultivares de Lotus spp., e observaram diferentes efeitos do TC sobre a digestão e absorção de AA. Animais alimentados com $L$. corniculatus demostraram aumento tanto do fluxo de AA essenciais (AAE; 52\%) quanto AA não essenciais (AANE; 14\%). Quando alimentados com L. pedunculatus a resposta foi inferior; porém, com uma tendência semelhante (14\% e $8 \%$ para AAE e AANE, respectivamente). Quando avaliado o efeito do tratamento sobre a elevação da absorção aparente (porcentagem da ingestão) no intestino delgado, a concentração de AAE foi maior para ovinos alimentados com L. corniculatus (59\%) do que por $L$. pedunculatus (10\%). Em contraste, o TC reduziu a absorção aparente de AANE em 10\% do consumo de ovinos alimentados com $L$. corniculatus, mas não teve efeito para ovinos alimentados com $L$. pedunculatus. Esses resultados demonstram que nem todos os TC são biologicamente ativos ou expressam uma reatividade igual. Diferentes espécies de plantas podem apresentar diferença no seu grau 
de atividade biológica. Portanto a interação entre a concentração de TC e o fluxo de nitrogênio amoniacal pode ser específico para cada espécie forrageira.

Aerts et al. (1999) também afirmam que as proantocianidinas (TC) podem exercer efeitos no organismo devido à sua capacidade para complexar com proteínas. Forragens contendo concentrações moderadas de TC (2-4\% da MS) podem exercer efeitos benéficos sobre o metabolismo proteico em ovinos, diminuindo a degradação da proteína dietética em amônia no rúmen por microrganismos e aumentando o fluxo de proteína do rúmen para o intestino delgado, assim, permitindo maior absorção de aminoácidos. O que resulta em aumentos na lactação, crescimento de lã e ganho de peso, sem alterar o consumo voluntário de alimento.

Esses complexos formados pela combinação de TC-proteína no ambiente ruminal, permite um aumento da eficiência da reciclagem da ureia no rúmen, pela diminuição da atividade das desaminases bacterianas, que acabam reduzindo as concentrações de $\mathrm{N}$ - amoniacal no rúmen e $\mathrm{N}$-ureico plasmático, levando a uma menor perda de $\mathrm{N}$ via urina, permitindo maior reciclagem de $\mathrm{N}$ no rúmen aumentando a retenção deste nutriente no organismo animal em níveis moderados (Barry \& McNabb, 1999).

\section{Taninos e produção de metano $\left(\mathrm{CH}_{4}\right)$}

O metano é um dos produtos resultantes da fermentação dos nutrientes pelos microrganismos ruminais, assim como o gás dióxido de carbono $\left(\mathrm{CO}_{2}\right)$, que são eliminados por meio da eructação e respiração. Além desses gases, a amônia, células microbianas e os ácidos graxos voláteis (usados pelo ruminante como fonte de energia) também são produtos dessa fermentação (Hobson \& Stewart, 2012).

As bactérias responsáveis pela produção de $\mathrm{CH}_{4}$ são as Archaea metanogênicas (gêneros Methanobrevibacter, Methanobacterium, Methanomicrobium e Methanosarcina). As Archaea têm grande afinidade em sintetizar $\mathrm{CH}_{4}$ a partir de $\mathrm{H}_{2}$ e CO 2 para gerar suas necessidades energéticas para $\mathrm{o}$ crescimento (Miller, 1995; Murray et al., 1976). Apesar de produzirem $\mathrm{CH}_{4}$, essas bactérias são de extrema importância para o funcionamento do rúmen e manutenção da fermentação, mesmo representando uma pequena parte da fauna microbiana (Cunha et al., 2011; Morgavi et al., 2006). No rúmen, essas bactérias são encontradas associadas a protozoários ciliados e justapostas com bactérias. Esse processo para formação de metano requer energia, o que acaba tendo um custo para o animal, na literatura encontramos valores entre 6 a $18 \%$ de energia bruta da dieta perdida durante o processo de formação do $\mathrm{CH}_{4}$ (Berchielli et al., 2011).

A produção deste gás pelos ruminantes está estritamente relacionada com o manejo nutricional. Portanto, existe a possibilidade da redução na produção desse gás pela modificação da fermentação ruminal, possibilitando tornar o processo de produção de alimentos mais eficiente e também contribuir com a redução do aquecimento global (Hammond et al., 2015; Johnson \& Johnson, 1995), já que a produção animal sustentável tem sido o foco de pesquisa em todo mundo, frente às mudanças climáticas globais. Desde o início da década passada, a FAO tem alertado sobre o impacto da emissão de metano pelos ruminantes no meio ambiente e tornou como prioritária a pesquisa na emissão de metano nos sistemas agropecuários mundiais, pois as pastagens ocupam dois terços da área agricultável no mundo e grande parte do território brasileiro (Ferraz \& Felício, 2010).

Os taninos são considerados um grupo promissor de compostos para auxiliar na redução das emissões de metano (CH4) por parte dos ruminantes (Jeronimo et al., 2016). Woodward et al. (2001) sugerem que os taninos apresentam efeito deletério sobre as bactérias metanogênicas, pela redução na produção de $\mathrm{H}_{2}$, como consequência da redução na digestibilidade da fibra, e por efeito inibitório direto na população. Desta forma, promovem uma redução na emissão de metano e consequentemente, uma maior eficiência na utilização de energia pelos ruminantes, melhorando o desempenho animal. Tavendale et al. (2005) também sugerem que a inibição de crescimento de metanogênicas pode estar relacionado com os efeitos bacteriostáticos e/ou bactericidas dos TC.

A remoção dos protozoários, também podem reduzir a produção de $\mathrm{CH}_{4}$, pela característica que as Archaea metanogênicas possuem em se "acoplarem" a esta classe de microrganismo (Patra \& Saxena, 2010). A redução na produção de CH4 foi constatada em cordeiros alimentados com L. pedunculatus, devido a presença de TC, uma redução significativa de $16 \%$ de produção (Waghorn et al., 2002). 
Um estudo in vitro foi realizado por Tan et al. (2011) para avaliar os efeitos do TC oriundos da Leucaena leucocephala sobre a produção de metano, fermentação ruminal e população de metanogênicas e protozoários. Os autores testaram níveis crescentes de TC $(0,10,15,20,25$ e $30 \mathrm{mg}$ para cada $500 \mathrm{mg}$ de MS) e os resultados sugeriram que um nível mais baixo de TC $(15 \mathrm{mg} / 500 \mathrm{mg}$ de MS) apresentou uma redução de $47 \%$ na produção de $\mathrm{CH}_{4}$ e apenas $7 \%$ de redução na digestibilidade da MS. No entanto, as inclusões mais elevadas de TC apresentaram reduções ainda maiores na produção de $\mathrm{CH} 4$, porém acarretaram em efeitos negativos sobre a digestibilidade de MS. As estimativas de bactérias metanogênicas e protozoários mostrou reduções lineares com níveis crescentes de TC.

Quando utilizado baixos níveis (0 a $2 \%$ da MS) de extrato de TC oriundos do Quebracho, Beauchemin et al. (2007) não observaram efeitos sobre as emissões de metano em bovinos. Afirmando que concentrações de $2 \%$ de TC na MS da dieta não causa efeito sobre a produção de metano entérico em bovinos de corte em crescimento. Trabalho realizado por Puchala et al. (2005) alimentando caprinos com Sericea lespedeza $(17,7 \%$ de TC na matéria seca) e uma mistura de Digitaria ischaemum com Festuca arundinacea $(0,5 \%$ de TC na matéria seca), verificaram uma redução de $30 \%$ na produção de metano pelos animais que consumiram um elevado teor de TC na dieta, reduzindo de 10,6g para 7,4g de metano produzido por dia.

\section{Efeito anti-helmíntico do TC}

O sistema pastoril se destaca por ser uma alternativa economicamente sustentável na criação de ruminantes. Entretanto, nesse ecossistema a produção de bovinos e ovinos é acometida pelo maior problema sanitário, que são as infecções por nematoides parasitas do trato gastrintestinal (NGI). Resultando na depressão do consumo de alimentos, perda de peso, mortalidade, custos com tratamentos, redução na deposição de tecido e crescimento do esqueleto, e principalmente por provocar a ineficiência do aproveitamento dos nutrientes pelo hospedeiro (Pathak, 2013).

Na tentativa de resolução do problema, com o objetivo de assegurar que a população de parasitas não exceda níveis prejudiciais à produtividade dos animais e, por consequência não inviabilize a atividade econômica, lançou-se mão do uso indiscriminado de drogas anti-helmínticas (Amarante, 2009). Todavia, seu uso contínuo teve como consequência a seleção de populações de helmintos com resistência aos diferentes grupos químicos utilizados no tratamento dos animais ( $\underline{\text { Schnyder et al., 2005; }}$ Scott et al., 2013; Taylor et al., 2009). Diante deste empasse, diferentes métodos têm sido utilizados no intuito de minimizar o impacto negativo dessas doenças para a produção de ruminantes.

Dentre as alternativas, ganha destaque na literatura atual o uso de compostos secundários das plantas, como o tanino condensado (TC), que tem sido caracterizado com propriedades anti-helmínticas. $\mathrm{O}$ fornecimento forragens ou alimentos que contêm TC na alimentação de ruminantes tem potencial para auxiliar na mitigação do problema com parasitas gastrointestinais (Naumann et al., 2017). Segundo Athanasiadou et al. (2001), duas hipóteses podem explicar esse efeito dos TC contra os helmintos. A primeira um efeito direto dos TC sobre as larvas infectantes e parasitas adultos, impedindo o desembainhamento (ligação do TC com a cutícula da larva rica em glicoproteínas), diminuindo a fecundidade das fêmeas, deprimindo a disponibilidade de nutrientes para o crescimento através da inibição da fosforilação oxidativa e diminuindo o metabolismo da mesma. A segunda sugere um aumento da resistência e resiliência do hospedeiro, pelo efeito indireto dos TC, melhorando a utilização proteica e, consequentemente, melhor resposta imune deste aos parasitas e maior aporte de proteína para reparação dos tecidos lesionados.

A contagem de ovos de NGI nas fezes (OPG) de caprinos alimentados com dietas contendo níveis de $25 \%, 50 \%$, e $75 \%$ de feno de Lespedeza cuneata (Sericea lespedeza), com concentração de TC de $24,5,49$, e $73 \mathrm{~g}$ de $\mathrm{TC} / \mathrm{kg}$ de MS, respectivamente tiveram respostas diferentes em trabalho realizado por Terrill et al. (2009). Ao nível de $25 \%$ não observaram redução do OPG. No entanto, em ambos os níveis de $50 \%$ e $75 \%$, a diminuição do OPG foi de $84,6 \%$ e $91,9 \%$, respectivamente. Além da redução do OPG, quando adicionado o feno a um nível de $75 \%$ na dieta houve diminuição do estabelecimento das larvas infectantes (L3) e larvas adultas.

Paolini et al. (2003) avaliaram o possível impacto do extrato de TC de Quebracho (5\% da MS) em cabras infectadas com larvas adultas de Haemonchus contortus. Os resultados foram positivos na 
diminuição de OPG durante todo o período experimental, apesar de não terem encontrado redução na contagem do número de larvas. No entanto, houve uma diminuição significativa na fecundidade das larvas fêmeas. Estudo realizado por Pathak (2013) utilizando ovelhas infectadas com Haemonchus contortus suplementadas com TC (1,5\% da MS) concluíram um impacto positivo sobre os parâmetros hematológicos e efeito inibitório sobre a intensidade de infecção do $H$. contortus. Outro trabalho avaliou a resposta do uso de TC sobre a redução nas larvas infectantes (L3) e adultas de NGI em cabras Boer recebendo dieta com $75 \%$ de feno de Sericea lespedeza ( $224 \mathrm{~g}$ de TC/kg de MS), e observaram redução de $88 \%$ de larvas (Shaik et al., 2006). Shalders et al. (2014) registraram controle de parasitos gastrointestinais com máximo desempenho utilizando a adição de $20-30 \%$ de torta de pimenta rosa que é uma planta rica em TC na dieta de caprinos.

O uso de forragens contendo TC pode auxiliar no controle de NGI, como observado nos estudos citados. Os TC apresentam potencial para diminuir a carga parasitária e desenvolvimento larval, o que possivelmente levaria a uma diminuição na contaminação das pastagens e menos dependência no uso de produtos químicos para o controle das infecções.

\section{Conclusão}

A área da produção animal que estuda a nutrição de ruminantes tem buscado cada vez mais alternativas para maximizar a eficiência do ambiente ruminal, principalmente quando se refere à capacidade de melhorar a qualidade e disponibilidade de proteína metabolizável. O crescente interesse pelo uso de compostos secundários das plantas na dieta de ruminantes vem mostrando resultados interessantes na produção animal. O TC em baixa e média concentração pode ser uma boa estratégia nutricional para os ruminantes, uma vez que ele altera a fermentação ruminal e consequentemente o desempenho animal. Porém, ainda existe alguns questionamentos que precisam ser melhor definidos nessa linha de pesquisa, relacionados com a variação da estrutura química do TC e as diferentes interações com as proteínas. Pois não se definiu ao certo qual a porcentagem de TC na MS ideal de uma determinada planta para uma melhor resposta no desempenho animal, seja esse voltado para a capacidade de se complexar as proteínas, redução de metano ou até mesmo como efeito anti-helmíntico.

\section{Referências}

Aerts, R. J., Barry, T. N., \& McNabb, W. C. (1999). Polyphenols and agriculture: beneficial effects of proanthocyanidins in forages. Agriculture, Ecosystems \& Environment, 75(1), 1-12. DOI: https://doi.org/10.1016/s0167-8809(99)00062-6

Alonso-Díaz, M. A., Torres-Acosta, J. F. J., Sandoval-Castro, C. A., \& Hoste, H. (2010). Tannins in tropical tree fodders fed to small ruminants: a friendly foe? Small Ruminant Research, 89(2-3), 164173. DOI: https://doi.org/10.1016/j.smallrumres.2009.12.040

Amarante, A. F. T. (2009). Nematoides gastrintestinais em ovinos. In Doenças parasitárias de caprinos e ovinos: epidemiologia e controle (pp. 19-61). Brasília: Embrapa Informação Tecnológica.

Athanasiadou, S., Kyriazakis, I., Jackson, F., \& Coop, R. L. (2001). Direct anthelmintic effects of condensed tannins towards different gastrointestinal nematodes of sheep: in vitro and in vivo studies. Veterinary Parasitology, 99(3), 205-219. DOI: https://doi.org/10.1016/S0304-4017(01)00467-8

Barry, T. N., \& Duncan, S. J. (1984). The role of condensed tannins in the nutritional value of Lotus pedunculatus for sheep: 1. Voluntary intake. British Journal of Nutrition, 51(3), 485-491. DOI: https://doi.org/10.1079/bjn19860141

Barry, T. N., \& Manley, T. R. (1984). The role of condensed tannins in the nutritional value of Lotus pedunculatus for sheep: 2. Quantitative digestion of carbohydrates and proteins. British Journal of Nutrition, 51(3), 493-504. DOI: https://doi.org/10.1079/bjn19860141

Barry, T. N., \& McNabb, W. C. (1999). The implications of condensed tannins on the nutritive value of temperate forages fed to ruminants. British Journal of Nutrition, 81(4), 263-272. DOI: https://doi.org/10.1017/S0007114599000501

Bate-Smith, E. C. (1962). The phenolic constituents of plants and their taxonomic significance. I. Dicotyledons. Botanical Journal of the Linnean Society, 58(371), 95-173. DOI: https://doi.org/10.1111/j.1095-8339.1962.tb00890.x 
Beauchemin, K. A., McGinn, S. M., Martinez, T. F., \& McAllister, T. A. (2007). Use of condensed tannin extract from quebracho trees to reduce methane emissions from cattle. Journal of Animal Science, 85(8), 1990-1996. DOI: https://doi.org/10.2527/jas.2006-686

Berchielli, T. T., Pires, A. V, Oliveira, S. G., \& FUNEP. (2011). Nutrição de Ruminantes (Issue 2th ed.). FUNEP.

Bruneton, J. (1995). Pharmacognosy, phytochemistry, medicinal plants. Lavoisier Publishing.

Cagle, C. M., Fonseca, M. A., Callaway, T. R., Runyan, C. A., Cravey, M. D., \& Tedeschi, L. O. (2020). Evaluation of the effects of live yeast on rumen parameters and in situ digestibility of dry matter and neutral detergent fiber in beef cattle fed growing and finishing diets. Applied Animal Science, 36(1), 36-47. DOI: https://doi.org/10.15232/aas.2019-01888

Cocito, C. (1979). Antibiotics of the virginiamycin family, inhibitors which contain synergistic components. Microbiological Reviews, 43(2), 145-198. DOI: https://doi.org/10.1128/mmbr.43.2.145-192.1979

Cunha, I. S., Barreto, C. C., Costa, O. Y. A., Bomfim, M. A., Castro, A. P., Kruger, R. H., \& Quirino, B. F. (2011). Bacteria and Archaea community structure in the rumen microbiome of goats (Capra hircus) from the semiarid region of Brazil. Anaerobe, 17(3), 118-124. DOI: http://dx.doi.org/10.1016/j.anaerobe.2011.04.018

Ferraz, J. B. S., \& Felício, P. E. (2010). Production systems - An example from Brazil. Meat Science, 84(2), 238-243. DOI: https://doi.org/10.1016/j.meatsci.2009.06.006

Frutos, P., Hervas, G., Giráldez, F. J., \& Mantecón, A. R. (2004). Review. Tannins and ruminant nutrition. Spanish Journal of Agricultural Research, 2(2), 191-202. DOI: https://doi.org/10.5424/sjar/2004022-73

Frutos, P., Hervás, G., Ramos, G., Giráldez, F. J., \& Mantecon, A. R. (2002). Condensed tannin content of several shrub species from a mountain area in northern Spain, and its relationship to various indicators of nutritive value. Animal Feed Science and Technology, 95(3-4), 215-226. DOI: https://doi.org/10.1016/S0377-8401(01)00323-6

Goodrich, R. D., Garrett, J. E., Gast, D. R., Kirick, M. A., Larson, D. A., \& Meiske, J. C. (1984). Influence of monensin on the performance of cattle. Journal of Animal Science, 58(6), 1484-1498. DOI: https://doi.org/10.2527/jas1984.5861484x

Hammond, K. J., Humphries, D. J., Crompton, L. A., Green, C., \& Reynolds, C. K. (2015). Methane emissions from cattle: estimates from short-term measurements using a GreenFeed system compared with measurements obtained using respiration chambers or sulphur hexafluoride tracer. Animal Feed Science and Technology, 203, 41-52. DOI: https://doi.org/10.1016/j.anifeedsci.2015.02.008

Hart, K. J., Yáñez-Ruiz, D. R., Duval, S. M., McEwan, N. R., \& Newbold, C. J. (2008). Plant extracts to manipulate rumen fermentation. Animal Feed Science and Technology, 147(1-3), 8-35. DOI: http://dx.doi.org/10.1016/j.anifeedsci.2007.09.007

Haslam, E. (1989). Plant polyphenols: vegetable tannins revisited. Cambridge University Press.

Hobson, P. N., \& Stewart, C. S. (2012). Rumen microbial ecosystem (2nd ed.). Blackie Academic \& Professional.

Huang, Q., Liu, X., Zhao, G., Hu, T., \& Wang, Y. (2018). Potential and challenges of tannins as an alternative to in-feed antibiotics for farm animal production. Animal Nutrition, 4(2), 137-150. DOI: https://doi.org/10.1016/j.aninu.2017.09.004

Jeronimo, E., Pinheiro, C., Lamy, E., Dentinho, M. T., Sales-Baptista, E., Lopes, O., \& e Silva, F. C. (2016). Tannins: Biochemistry, food sources and nutritional properties. Nova Science Publishers, 1 , $1-190$.

Johnson, K. A., \& Johnson, D. E. (1995). Methane emissions from cattle. Journal of Animal Science, 73(8), 2483-2492. DOI: http://dix.doi.org//10.2527/1995.7382483x

Kamra, D. N. (2005). Rumen microbial ecosystem. Current Science, 89(1), 124-135.

Kumar, R., \& Singh, M. (1984). Tannins: their adverse role in ruminant nutrition. Journal of Agricultural and Food Chemistry, 32(3), 447-453. DOI: https://doi.org/10.1021/jf00123a006 
Kyriazakis, I., Athanasiadou, S., \& Giannenas, I. (2010). Nutritional strategies to control gastrointestinal parasitism in small ruminants. Advances in Animal Biosciences, 1(2), 390-391. DOI: https://doi.org/10.1017/s204047001000018x

Leinmüller, E., Steingass, H., \& Menke, K. H. (1991). Tannins in ruminant feedstuffs. Biannual Collection of Recent German Contributions Concerning Development through Animal Research, 33, 9-62.

Lotfi, R. (2020). A commentary on methodological aspects of hydrolysable tannins metabolism in ruminant: a perspective view. Letters in Applied Microbiology, 71(5), 466-478. DOI: https://doi.org/10.1111/lam.13346

Makkar, H. P. S., Blümmel, M., \& Becker, K. (1995). Formation of complexes between polyvinyl pyrrolidones or polyethylene glycols and tannins, and their implication in gas production and true digestibility in in vitro techniques. British Journal of Nutrition, 73(6), 897-913. DOI: https://doi.org/10.1079/bjn19950095

McMahon, L. R., McAllister, T. A., Berg, B. P., Majak, W., Acharya, S. N., Popp, J. D., Coulman, B. E., Wang, Y., \& Cheng, K.-J. (2000). A review of the effects of forage condensed tannins on ruminal fermentation and bloat in grazing cattle. Canadian Journal of Plant Science, 80(3), 469-485. DOI: https://doi.org/10.4141/P99-050

McSweeney, C. S., Palmer, B., McNeill, D. M., \& Krause, D. O. (2001). Microbial interactions with tannins: nutritional consequences for ruminants. Animal Feed Science and Technology, 91(1), 8393. DOI: https://doi.org/10.1016/S0377-8401(01)00232-2

Miller, T. L. (1995). Ecology of methane production and hydrogen sink in the rumen. In W. V Engelhardt, S. Leonhard-Marek, G. Breves, \& D. Giessecke (Eds.), Ruminant physiology: Digestion, metabolism, growth and reproduction (pp. 317-332). Ferdinand Enke Verlag.

Minho, A. P., Bueno, I. C. S., Gennari, S. M., Jackon, F., \& Abdalla, A. L. (2008). In vitro effect of condensed tannin extract from acacia (Acacia mearnsii) on gastrointestinal nematodes of sheep. Revista Brasileira de Parasitologia Veterinária, 17(1), 144-148.

Morgavi, D. P., Jouany, J. P., Martin, C., \& Ranilla, M. J. (2006). Archaeal community structure diversity in the rumen of faunated and defaunated sheep. International Congress Series, 1293(1), 127-130. DOI: http://dx.doi.org/10.1016/j.ics.2006.01.019

Muir, J. P. (2011). The multi-faceted role of condensed tannins in the goat ecosystem. Small Ruminant Research, 98(1-3), 115-120. DOI: http://dx.doi.org/10.1016/j.smallrumres.2011.03.028

Murray, R. M., Bryant, A. M., \& Leng, R. A. (1976). Rates of production of methane in the rumen and large intestine of sheep. British Journal of Nutrition, 36(1), 1-14. DOI: https://doi.org/10.1079/bjn19760053

Nagaraja, T. G., Newbold, C. J., Van Nevel, C. J., \& Demeyer, D. I. (2012). Manipulation of ruminal fermentation. In P. N. Hobson \& C. S. Stewart (Eds.), The rumen microbial ecosystem (Vol. 1, pp. 523-632). Black Acaddemic \& Professional. DOI: https://doi.org/10.1007/978-94-009-1453-7 13

Narjisse, H., Elhonsali, M. A., \& Olsen, J. D. (1995). Effects of oak (Quercus ilex) tannins on digestion and nitrogen balance in sheep and goats. Small Ruminant Research, 18(3), 201-206. DOI: https://doi.org/10.1016/0921-4488(95)00700-0

Naumann, H. D., Tedeschi, L. O., Zeller, W. E., \& Huntley, N. F. (2017). The role of condensed tannins in ruminant animal production: advances, limitations and future directions. Revista Brasileira de Zootecnia, 46(12), 929-949. DOI: https://doi.org/10.1590/S1806-92902017001200009

Paolini, V., Bergeaud, J.-P., Grisez, C., Prevot, F., Dorchies, P., \& Hoste, H. (2003). Effects of condensed tannins on goats experimentally infected with Haemonchus contortus. Veterinary Parasitology, 113(3-4), 253-261. DOI: https://doi.org/10.1016/S0304-4017(03)00064-5

Pathak, A. K. (2013). Potential of using condensed tannins to control gastrointestinal nematodes and improve small ruminant performance. International Journal of Molecular Veterinary Research, 3(1), 36-50. DOI: https://doi.org/10.5376/ijmvr.2013.03.0008

Patra, A. K., \& Saxena, J. (2010). A new perspective on the use of plant secondary metabolites to inhibit methanogenesis in the rumen. Phytochemistry, 71(11-12), 1198-1222. DOI: 
https://doi.org/10.1016/j.phytochem.2010.05.010

Puchala, R., Min, B. R., Goetsch, A. L., \& Sahlu, T. (2005). The effect of a condensed tannin-containing forage on methane emission by goats. Journal of Animal Science, 83(1), 182-186. DOI: https://doi.org/10.2527/2005.831182x

Reed, J. D. (1995). Nutritional toxicology of tannins and related polyphenols in forage legumes. Journal of Animal Science, 73(5), 1516-1528. DOI: http://dx.doi.org/10.2527/1995.7351516x

Schnyder, M., Torgerson, P. R., Schönmann, M., Kohler, L., \& Hertzberg, H. (2005). Multiple anthelmintic resistance in Haemonchus contortus isolated from South African Boer goats in Switzerland. Veterinary Parasitology, 128(3-4), 285-290. DOI: https://doi.org/10.1016/j.vetpar.2004.12.010

Scott, I., Pomroy, W. E., Kenyon, P. R., Smith, G., Adlington, B., \& Moss, A. (2013). Lack of efficacy of monepantel against Teladorsagia circumcincta and Trichostrongylus colubriformis. Veterinary Parasitology, 198(1-2), 166-171. DOI: https://doi.org/10.1016/j.vetpar.2013.07.037

Seigler, D. S. (2003). Phytochemistry of Acacia—sensu lato. Biochemical Systematics and Ecology, 31(8), 845-873. DOI: http://dx.doi.org/10.1016/S0305-1978(03)00082-6

Sgarbieri, V. C. (1996). Proteínas em alimentos protéicos: propriedades-degradações-modificações. Livraria Varela.

Shaik, S. A., Terrill, T. H., Miller, J. E., Kouakou, B., Kannan, G., Kaplan, R. M., Burke, J. M., \& Mosjidis, J. A. (2006). Sericea lespedeza hay as a natural deworming agent against gastrointestinal nematode infection in goats. Veterinary Parasitology, 139(1-3), 150-157. DOI: https://doi.org/10.1016/j.vetpar.2006.02.020

Shalders, E., Zanini, S. F., de Sousa, D. R., Barioni, G., Clipes, R. C., Avelar, B. R., \& Suhet, J. M. M. (2014). Percentual de suplementação de fonte taninífera na ração concentrada de caprinos jovens sobre o desempenho e carga parasitária. Ciência Rural, 44(6), 1100-1105. DOI: https://doi.org/10.1590/s0103-84782014000600024

Stewart, C. S., Flint, H. J., \& Bryant, M. P. (2012). The rumen bacteria. In P. N. Hobson \& C. S. Stewart (Eds.), Rumen microbial ecosystem (2nd ed., Vol. 1, pp. 10-72). Blackie Academic \& Professional. DOI: https://doi.org/10.1007/978-94-009-1453-7__2

Tan, H. Y., Sieo, C. C., Abdullah, N., Liang, J. B., Huang, X. D., \& Ho, Y. W. (2011). Effects of condensed tannins from Leucaena on methane production, rumen fermentation and populations of methanogens and protozoa in vitro. Animal Feed Science and Technology, 169(3-4), 185-193. DOI: http://dx.doi.org/10.1016/j.anifeedsci.2011.07.004

Tavendale, M. H., Meagher, L. P., Pacheco, D., Walker, N., Attwood, G. T., \& Sivakumaran, S. (2005). Methane production from in vitro rumen incubations with Lotus pedunculatus and Medicago sativa, and effects of extractable condensed tannin fractions on methanogenesis. Animal Feed Science and Technology, 123-124, 403-419. DOI: https://dx.doi.org/10.1016/j.anifeedsci.2005.04.037

Taylor, M. A., Learmount, J., Lunn, E., Morgan, C., \& Craig, B. H. (2009). Multiple resistance to anthelmintics in sheep nematodes and comparison of methods used for their detection. Small Ruminant Research, 86(1-3), 67-70. DOI: https://doi.org/10.1016/j.smallrumres.2009.09.020

Tedeschi, L. O., Ramírez-Restrepo, C. A., \& Muir, J. P. (2014). Developing a conceptual model of possible benefits of condensed tannins for ruminant production. Animal, 8(7), 1095. https://doi.org/10.1017/S1751731114000974

Terrill, T. H., Dykes, G. S., Shaik, S. A., Miller, J. E., Kouakou, B., Kannan, G., Burke, J. M., \& Mosjidis, J. A. (2009). Efficacy of sericea lespedeza hay as a natural dewormer in goats: dose titration study. Veterinary Parasitology, 163(1-2), 52-56. DOI: https://doi.org/10.1016/j.vetpar.2009.04.022

Valadares Filho, S. C., Pina, D. S., \& FUNEP. (2011). Fermentação ruminal. In T. T. Berchielli, A. V Pires, \& S. G. Oliveira (Eds.), Nutrição de Ruminantes (Issue 2th ed., pp. 161-192). FUNEP.

Van Soest, P. J. (1994). Nutritional ecology of the ruminant (Vol. 1, Issue 2). Cornell University Press.

Waghorn, G. (2008). Beneficial and detrimental effects of dietary condensed tannins for sustainable sheep and goat production-Progress and challenges. Animal Feed Science and Technology, 147(13), 116-139. DOI: https://doi.org/10.1016/j.anifeedsci.2007.09.013 
Waghorn, G. C., Jones, W. T., Shelton, I. D., \& McNabb, W. C. (1990). Condensed tannins and the nutritive value of herbage. Proceedings of the New Zealand Grassland Association, 51, 171-176. DOI: https://doi.org/10.33584/jnzg.1990.51.1894

Waghorn, G. C., Tavendale, M. H., \& Woodfield, D. R. (2002). Methanogenesis from forages fed to sheep. Proceedings of the New Zealand Grassland Association, 64, 167-171. DOI: https://doi.org/10.33584/jnzg.2002.64.2462

Woodward, S. L., Waghorn, G. C., Ulyatt, M. J., \& Lassey, K. R. (2001). Early indications that feeding Lotus will reduce methane emissions from ruminants. Proceeding - New Zealand Society of Animal Production, 61, 23-26.

Yoshihara, E., Minho, A. P., \& Yamamura, M. H. (2013). Efeito anti-helmíntico de taninos condensados em nematódeos gastrintestinais de ovinos (Ovis aries). Semina: Ciências Agrárias, 34(2), 39353949. DOI: https://doi.org/10.5433/1679-0359.2013v34n6supl2p3935.

\section{Histórico do artigo:}

Recebido: 14 de agosto de 2020.

Aprovado: 12 de outubro de 2020 .

Disponível online: 26 de janeiro de 2021.
Licenciamento: Este artigo é publicado na modalidade Acesso Aberto sob a licença Creative Commons Atribuição 4.0 (CC-BY 4.0), a qual permite uso irrestrito, distribuição, reprodução em qualquer meio, desde que o autor e a fonte sejam devidamente creditados. 